\title{
Syndromic association of cleft palate, bilateral choanal atresia, curly hair, and congenital hypothyroidism
}

\author{
I M Buntincx, B Van Overmeire, K Desager, J Van Hauwaert
}

\begin{abstract}
We describe a patient with the unusual association of cleft palate, bilateral choanal atresia, curly hair, and congenital hypothyroidism. This association has been reported before in two brothers and may represent a new syndrome.

(f Med Genet 1993;30:427-8)

Cleft palate, choanal atresia, curly hair, and, to a much lesser extent, congenital hypothyroidism are components of well defined syndromes. The association, however, of these four features is very uncommon and has been described in only two patients. ${ }^{1}$ We report here a third case with this association.
\end{abstract}

\section{Case report}

This girl was the second child of non-consanguineous parents; the father and mother were 32 and 29 years old respectively at the birth of this child. The family history was unremarkable. Abuse of drugs, alcohol, or nicotine during pregnancy was denied. Routine ultrasonography in the 33rd week of pregnancy showed polyhydramnios; the biparietal diameter was on the 90 th centile.

The child was born at 36 weeks' gestation by uncomplicated breech delivery. The amount of amniotic fluid was estimated to be 41 . Birth weight was $2580 \mathrm{~g}$ (25th centile), length $47.6 \mathrm{~cm}$ (25th to 50 th centile), and head circumference $34.8 \mathrm{~cm}$ (90th centile). Because of respiratory distress the child was immediately transferred to our neonatal intensive care unit. Clinical examination on admission showed several abnormalities (figure). The hair was curly and grew over the forehead and the eyelashes were long. The ears were low set and deformed and there was micrognathia. Inspection of the mouth showed cleft palate. As intubation through the nose and positioning of a nasal catheter proved impossible, bilateral choanal atresia was suspected. Other findings were dark skin, generalised hirsutism, hypertrophy of the clitoris, and bilateral simple palmar crease. There was generalised hypotonia. Oral intubation and artificial respiration were applied and, because of the extreme feeding difficulties, a gastrostomy was performed. During screening for hypothyroidism on day 2 , high values for TSH (more than $50 \mu \mathrm{U} / \mathrm{ml}$, normal value $0 \cdot 15$ to $5 \cdot 5 \mu \mathrm{U} / \mathrm{ml}$ ), low values for $\mathrm{FT}_{4}(1.9 \mathrm{pmol} / \mathrm{l}$, normal value 9.0 to $22.5 \mathrm{pmol} / \mathrm{l}$ ), and low values for $\mathrm{FT}_{3}$ (less than $0.04 \mathrm{pmol} / \mathrm{l}$, normal value 3.5 to $9.0 \mathrm{pmol} / \mathrm{l}$ ) were observed. Hypothyroidism was con-
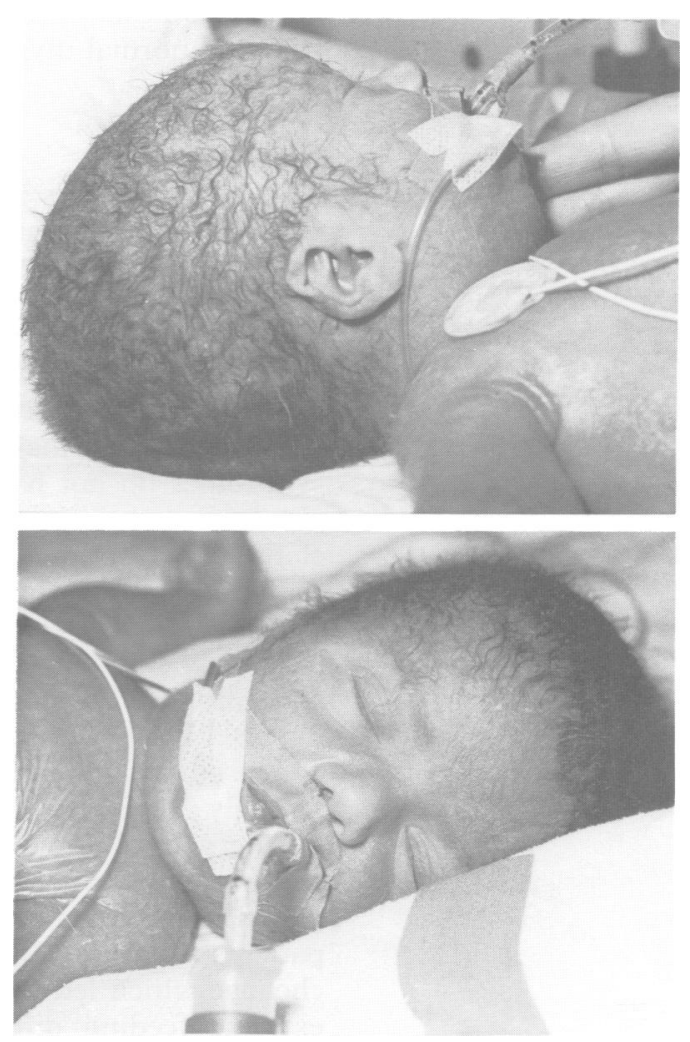

The patient on admission. Note the peculiar hair, the low set, abnormal ears, and the micrognathia.

firmed later: on day $9 \mathrm{FT}_{4}$ was less than $0.10 \mathrm{pmol} / 1$ and $\mathrm{FT}_{3}$ less than $0.04 \mathrm{pmol} / \mathrm{l}$. Thyroglobulin was less than $0 \cdot 2 \mathrm{ng} / \mathrm{ml}$ (normal value 2 to $70 \mathrm{ng} / \mathrm{ml}$ ) and TSH receptor antibodies were within normal limits $(15 \mathrm{mU} / \mathrm{ml}$, normal value 9 to $14 \mathrm{mU} / \mathrm{ml}$ ). Treatment with L-thyroxin was started.

Further investigations comprised a contrast study of the nasal region which confirmed the obstruction, a CT scan of the nasopharynx which confirmed a midline cleft palate and a non-classical bilateral choanal obstruction, and an MRI scan which confirmed these findings. On examination of the hair by scanning electron microscopy, a slight reduction of the scaling pattern as compared with hair from children of the same age, but no pili torti, was observed. Ultrasound of the abdomen, fundoscopic examination, and echocardiography were normal.

Intubation was necessary until the age of 9 days. Three weeks after birth the hirsutism had disappeared, the hair was still curly, but had become more sparse. At discharge from the neonatal intensive care unit at the age of 7 weeks the skin had become fair and neuro- 
logical examination was normal. The child was readmitted at the age of 4 months. Ultrasonography of the neck showed a hypodense thyroid gland. Treatment with L-thyroxin was continued as laboratory results showed persistence of the hypothyroid status following a short interruption of the substitution therapy. The neuromotor development at that time was normal.

Both parents and an older brother are apparently healthy. They have normal stature, straight hair with normal structure, normal findings on examination of the nose and pharynx, and normal thyroid function.

\section{Discussion}

The main features in our patient are cleft palate, bilateral choanal atresia, peculiar curly hair, and congenital hypothyroidism. A number of syndromes have been described which associate one or more of the first three anomalies. They differ, however, from the clinical picture observed in our patient by the presence of other major anomalies. Also, these syndromes do not have congenital hypothyroidism as a component. Hypothyroidism and cleft palate were present in a girl described by Zadik et $a l,{ }^{2}$ but the other features, dermoid cysts of the eyelids, mild ectodermal dysplasia (dry scaly skin, sparse hair, and oligodontia), and mild facial dysmorphism (frontal bossing, hypertelorism) were absent in our patient.

The clinical picture in our patient, however, strongly resembles that described in two brothers by Bamforth et $a l^{1}$ in 1988. The features found in these two brothers and in our patient are compared in the table. In all three patients there was bilateral obstruction of the choanae which led to respiratory distress and extreme feeding difficulties in the neonatal period (J S Bamforth, personal communication) and a median cleft of the palate. Very probably the choanal atresia is also responsible for the polyhydramnios observed in the three cases. The three patients exhibited unusual spiky or curly hair which extended onto the forehead. Whereas in our patient hair exam-

Comparison of present patient with previously reported cases.

\begin{tabular}{lccc}
\hline & Patient $1^{1}$ & Patient $^{1}$ & $\begin{array}{c}\text { Present } \\
\text { case }\end{array}$ \\
\hline Sex & M & M & F \\
Bilateral choanal atresia & + & + & + \\
Median cleft palate & + & + & + \\
Sparse, curly/spiky hair & + & + & + \\
Congenital hypothyroidism & + & + & + \\
Polyhydramnios & + & + & + \\
Low set, abnormal ears & + & + & + \\
Micrognathia & + & + & + \\
Hypoplastic bifid epiglottis & + & + & + \\
Developmental delay & + & - & + \\
\hline
\end{tabular}

ination by scanning EM was normal, pili torti were seen in the patients of Bamforth et al. ${ }^{1}$ This may, however, have been because of the younger age of our patient as it is known that pili torti may appear only after some time. ${ }^{3}$ All three patients had congenital hypothyroidism. Whereas in the patients of Bamforth et al this resulted from agenesis of the thyroid gland, our patient had a small remnant of the gland but with insufficient function which necessitated substitution therapy. All three patients had micrognathia and low set ears with relatively flat upper helix and prominent anthelix. ${ }^{4}$ A feature which was present in the patients of Bamforth et al $^{1}$ but not in ours was the hypoplastic and bifid epiglottis. In contrast to the hypertonia in one of the patients of Bamforth et al $^{1}$ we observed hypotonia during the neonatal period. Whether the relatively increased head circumference at birth in our patient is also a part of the syndrome is unknown, as these details are not available for the patients of Bamforth et al. ${ }^{1}$ Physical growth was normal in one of the previous patients, but mild developmental delay was observed, possibly because of the late start of substitution therapy with thyroid hormone. The duration of the follow up in our patient is insufficient but examination at the age of 9 months showed mild motor developmental delay: the score on the motor Bayley scale was compatible with $5 \frac{1}{2}$ months and the mental Bayley development score was normal. The hyperpigmentation, hirsutism, and hypertrophy of the clitoris in our patient are probably not related to the syndrome as they disappeared spontaneously after a few weeks.

The cause of this syndrome is at present unknown: metabolic studies and chromosome analysis were normal in all three cases. No drug abuse during pregnancy was reported in our patient. The pattern of inheritance is uncertain, but autosomal recessive inheritance is suggested. $\mathrm{X}$ linked inheritance can be excluded as both sexes are affected. The finding of a right sided posterior choanal atresia in the mother of the two sibs described by Bamforth et al, ${ }^{1}$ may point towards autosomal dominant inheritance with variable expression. The absence of such anomalies in our patient's parents and the fact that unilateral choanal atresia is fairly common in women ${ }^{4}$ should, however, be taken into consideration.

1 Bamforth JS, Huch IA, Lazarus JA, Weaver CM, Harper PS. Congenital hypothyroidism, spiky hair and cleft

2 Zadik Z. Barak Y, Levin S. Case report 112. 7 Clin Dysmorphol 1983;1:24-7

3 Telfer N, Cutler TP, Dawler RPR. The natural history of pili torti. Br $\mathcal{F}$ Dermatol 1989;120:323-33.

4 Black RJ, Pracy R, Evans JNG. Congenital posterior choanal atresia. Clin Otolaryngol 1983;8:251-5. 